IP Periodica Polytechnica Mechanical Engineering

62(1), pp. 26-32, 2018

https://doi.org/10.3311/PPme.11003

Creative Commons Attribution (i)

RESEARCH ARTICLE

\section{Surface Structure Analysis of Syntactic Metal Foams Machined by Milling}

\author{
István Szalóki ${ }^{1 *}$, Zsolt János Viharos ${ }^{2}$
}

Received 08 May 2017; accepted after revision 14 September 2017

\begin{abstract}
In the automotive and aerospace industries the engineers are encouraged to develop new materials, having special features mainly for the purposes of mass reduction, favourable (specifi) mechanical properties, appropriate strength, heat resistance, and environmental impacts, becoming even more critical technically. The matrix of the metal matrix composite, being the subject of our research, is an AlMgSil aluminum alloy: it contains 50-55 volume per cent of $\mathrm{Al}_{2} \mathrm{O}_{3}$ particles as reinforcement, having an average diameter of $100-150 \mu \mathrm{m}$. After machining, the surface of materials, having such large particles, is divided by open cavities, therefore other methods have to be used in order to describe and characterise the surface structure than in the case of steel or aluminum components, having a homogeneous structure. In our present article the aim is to analyse the microgeometrical properties of the surface of metal matrix composite materials, produced to the tests and machined with shoulder milling; furthermore, the measures, being able to evaluate the produced surface in an exact way, will be determined.
\end{abstract}

\section{Keywords}

metal matrix composites, reinforcement, metal infiltration, diamond coating, arithmetical and longitudinal surface parameters

\section{Introduction}

In order to meet the market demands, the use of man-made composite materials is expected to grow tenfold in the future [1]. This forecast is confirmed by the expectations, awakened by the particularly favourable properties of composite materials, having different base materials. The primary objective of development of newer and newer metal matrix composites is to increase the mechanical strength, to make the friction and wear resistance more favourable, to influence the thermal expansion/stability, and the intention to reduce the mass while maintaining low density [4].

The machining of composite materials requires new approach not only from the point of view of cutting tool geometry and tool material, but also from the aspects of interpretation of surface quality, machined by the tool (roughness, waviness, layer properties etc.); moreover, in the qualification of working surfaces of components, too. The matrices of metallic composites (Al, Cu etc.) are usually soft, while the reinforcement is created by abrasive materials, have great hardness $\left(\mathrm{Al}_{2} \mathrm{O}_{3}, \mathrm{SiC}\right.$ etc $)$. The last-mentioned materials wear out the traditional milling tools to a greater extent and the cutting temperature increases during the machining, too. From a surface point of view it means that the surface quality will be changed as a result of the significant mechanical impact, caused by the thermal dilatation, microstructural changes and cutting forces. Considering the roughness of the machined surface, it can be noticed that the extremely rapid wear of tool is determinant: parallel with the development of the wear process, there is a constant change in the roughness: it oscillates often, but seeing its tendency, mostly it becomes worse.

\section{Materials and conditions of the milling tests}

The composite material is a multiphase material, containing base material (embedding-integrating, so-called matrix) and second phase (in case of structural materials, reinforcement, having a great strength and high elastic modulus). One of the components, determining the complex properties of composite materials, has a base material of lower strength, while the other, the load-bearing one, has a high strength value. The

\footnotetext{
${ }^{1}$ Department of Manufacturing Science and Engineering,

Faculty of Mechanical Engineering,

Budapest University of Technology and Economics,

H-1521 Budapest, Hungary

${ }^{2}$ Computer and Automation Research Institute,

Hungarian Academy of Sciences,

H-1518 Budapest, Hungary

*Corresponding author, e-mail: szaloki@manuf.bme.hu
}

I. Szalóki, Zs. J. Viharos 
Table 1 The properties of the particulate-reinforced composite materials, used during the tests [6-8]

\begin{tabular}{|c|c|c|c|c|c|c|}
\hline \multirow{3}{*}{$\begin{array}{l}\text { Matrix naterial } \\
\text { Main constituents, } \\
\text { per cent by weight }\end{array}$} & \multicolumn{6}{|c|}{ AlMgSi1 (ASM-equivalent: Al6061) } \\
\hline & $\mathrm{Al}$ & $\mathrm{Si}$ & $\mathrm{Mg}$ & $\mathrm{Cu}$ & Density, $\mathrm{g} / \mathrm{cm}^{3}$ & Tensile strength \\
\hline & 97 & 1 & 1.2 & 0.3 & 2.70 & 310 (UTS T6) \\
\hline \multicolumn{5}{|l|}{ Syntatic metal foams } & AMSF-SL150 & AMSF-SL300 \\
\hline \multicolumn{5}{|c|}{ Type of reinforcements } & SL150 & SL300 \\
\hline \multirow{2}{*}{\multicolumn{5}{|c|}{$\begin{array}{l}\text { Chemical compositions of reinforcement } \\
\text { (refers to both types of reinforcement) }\end{array}$}} & $55-65 \mathrm{wt} \% \mathrm{SiO}_{2}$ & $1-2 \mathrm{wt}^{0} \% \mathrm{Fe}_{2} \mathrm{O}_{3}$ \\
\hline & & & & & $30-36 \mathrm{wt} \% \mathrm{Al}_{2} \mathrm{O}_{3}$ & $0.5-1 \mathrm{wt} \% \mathrm{TiO}_{2}$ \\
\hline \multicolumn{5}{|c|}{ Average size of reinforcement, $\mu \mathrm{m}$} & 100 & 150 \\
\hline \multicolumn{5}{|c|}{ Size range of reinforcement, $\mu \mathrm{m}$} & $56-183$ & $101-330$ \\
\hline \multicolumn{5}{|c|}{ Microballoons $\%$ by volume, V\% } & 50.9 & 48.2 \\
\hline \multicolumn{5}{|c|}{ Average density of AMC. $\mathrm{g} / \mathrm{cm}^{3}$} & 1.42 & 1.51 \\
\hline
\end{tabular}

reinforcement can have continuous or granular structure, and it has two important tasks: on one hand, it makes a connection with the matrix material, on the other hand, it has to act as a load-mediator. These two components are able to resist highlevel mechanical stress only in case if there is a durable (adhesive) connection between them. In general, it can be stated that the properties of composites are determined by the quality and structure of the two components, mentioned earlier, by the morphology (shape) of the second phase and the boundary or so called interface layer between the components [5].

\section{The base materials, used during the tests}

The base materials, used to the tests, were produced in the Lab for Metal Matrix Composites at the Budapest University of Technology and Economics, Department for Materials Science and Engineering, with high-pressure infiltration (soaking) process. The essence of this procedure is that melted metal will be incorporated into the porous preform (under vacuum) under high pressure (approx. 36 bar). This process has the great advantage that the manufactured product is close to the final geometrical shape (,net-shape"), therefore it requires only few post-machining operations, being determinant from quality point of view [5]. The post-machining operations may be different types of cutting (sawing, water jet cutting, milling etc.).

In Table 1, the properties of the two types of syntactic metal foams (special particle-reinforced composite) and their base materials (matrix), machined by us, are summarised.

\section{The goal and conditions of the shoulder milling tests}

The primary objective of our study is to analyse the surfaces of syntactic metal foams (AMSF (aluminum matrix syntactic foam)), produced to the tests and machined by shoulder milling. Furthermore, it was also an objective of our study to characterise the milled surface structures with such measures, being able to evaluate the machined surface in an exact way and to refer somehow to the later working behaviour of the surface, too.
The cutting tests were executed in the workshop of Donát Bánki Faculty of Mechanical and Safety Engineering at Óbuda University, on MAZAK Nexus 410A machining center, serving mainly research purposes (having Mazatrol $^{\mathrm{TM}}$ control) and equipped with a device for blowing cold, compressed air $\left(\mathrm{CAG}^{\mathrm{TM}}\right)$. The main aim of setting the nozzles was to cool the so-called cutting zone, close to the tool edge, in an active way. When machining composite metal foams, having particulates, it is an essential requirement for health maintenance to take exhaust the dust-like formation (i. e. the very small chip elements), developing during the machining. It has been achieved also by using CAG: it delivered the detached material pieces into the inlet manifold of the exhaust equipment.

The cutting tests were carried out with a solid carbide metal end mill cutter (marking: B5640501), having a diameter of $12 \mathrm{~mm}, 3$ cutting edges and diamond coating, produced and provided by Fraisa; its condition prior to the tests has been checked by a stereomicroscope. Based on the experiences, gained during the preliminary tests $[9,10]$, it can be stated that the depth of cut has an irrelevant effect on the roughness. Due to this reason, the axial depth of cut $\left(a_{p}, m m\right)$ and the radial width of cut $\left(a_{e}\right.$, $\mathrm{mm}$ ) have been kept constant in case of shoulder milling operation of both syntactic metal foams. The values, changing during the tests, were cutting speed $\left(\mathrm{v}_{\mathrm{c}}, \mathrm{m} / \mathrm{min}\right)$ and feed rate per tooth $(\mathrm{f}, \mathrm{mm})$. The earlier mentioned values were altered on 3 , the last-mentioned on 5 variation levels (Table 2). 15 test settings have been carried out in a random order, the examinations were started with a tool in new condition per test material.

The table indicates that the metal foams were tested in the cutting speed range of $100 \leq \mathrm{v}_{\mathrm{c}}, \mathrm{m} / \mathrm{min} \leq 300$ and in case of feed rate per tooth the range was between $0.06 \leq \mathrm{f}_{\mathrm{z}}, \mathrm{mm} \leq 0.14$. In case of AlMgSi1 aluminum alloy (matrix material) an increased cutting speed value $\left(\mathrm{v}_{\mathrm{c}}=400 \mathrm{~m} / \mathrm{min}\right)$ was applied in order to avoid the formation of built-up edge, while the feed rate per tooth was kept constant. The aim of milling AlMgSi1 alloy was to obtain a clearer picture of the size and nature of differences in the structures of machined surfaces of matrix material and metal foams. 
Table 2 Milling conditions, the input parameters and levels of the whole factorial experimental plan

\begin{tabular}{|c|c|c|c|c|c|c|c|}
\hline \multicolumn{8}{|c|}{ Constant milling data } \\
\hline Axial depth of cut & Radial width of cut & Milled length & & Cooling & & Tool clamping & Radial run-out \\
\hline$a_{p}=6 \mathrm{~mm}$ & $\mathrm{a}_{\mathrm{e}}=2 \mathrm{~mm}$ & $1_{w}=70 \mathrm{~mm}$ & & $\mathrm{CAG}^{\mathrm{TM}}$ & & Cold-shrinking & $3-5 \mu \mathrm{m}$ \\
\hline \multicolumn{8}{|c|}{ Variable milling data } \\
\hline Grade & Levels & 1 & 2 & & 3 & 4 & 5 \\
\hline AMSF-SL150 & $\mathrm{v}_{\mathrm{c}}, \mathrm{m} / \mathrm{min}$ & 100 & 200 & & 300 & & \\
\hline AMSF-SL300 & $\mathrm{f}_{\mathrm{z}}, \mathrm{mm}$ & 0.06 & 0.08 & & 0.1 & 0.12 & 0.14 \\
\hline \multirow{2}{*}{ AlMgSi1 } & $\mathrm{v}_{\mathrm{c}}, \mathrm{m} / \mathrm{min}$ & 400 & & & & & \\
\hline & $\mathrm{f}_{\mathrm{z}}, \mathrm{mm}$ & 0.06 & 0.08 & & 0.1 & 0.12 & 0.14 \\
\hline
\end{tabular}

The analysis of the machined surface was carried out on a Mahr-Perthen Perthometer PRK Concept-2D-3D surface tester equipment, to the measurements a tracer, produced by Mahr and having a peak radius of $2 \mu \mathrm{m}$ and a taper angle of 90 degree, was used. The surface roughness measurements were performed, applying the following settings: applied traversing length $\left(\mathrm{L}_{\mathrm{t}}\right)=5.6 \mathrm{~mm}$, cut-off filtering wavelength $\left(\mathrm{L}_{\mathrm{c}}\right)=0.8$ $\mathrm{mm}$, evaluation length $\left(\mathrm{L}_{\mathrm{m}}\right)=4.0 \mathrm{~mm}$, applied traversing speed was $0.1 \mathrm{~mm} / \mathrm{s}$. The measurements were carried out geometrically in the same position and from the same position on the surface area, machined with shoulder milling: in a distance of 10, 30 and $50 \mathrm{~mm}$ from the place, entering the surface. In our present article we are going to publish the results, averaged from these three measurements and/or the rough results.

\section{Description of the milled surface of metal foams with roughness parameters}

There is a serial of well-tried and common parameters in order to describe the machined surface of steels [11]. As regards the characterisation of the machined surface of syntactic metal foams, another approach is necessary in order to be able to make the description of surface in an exact and effective way (Fig. 1).

AlMgSil

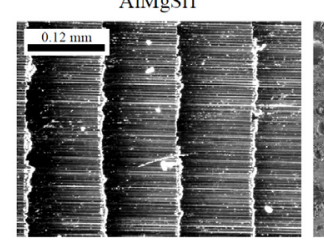

AMSF-SL150
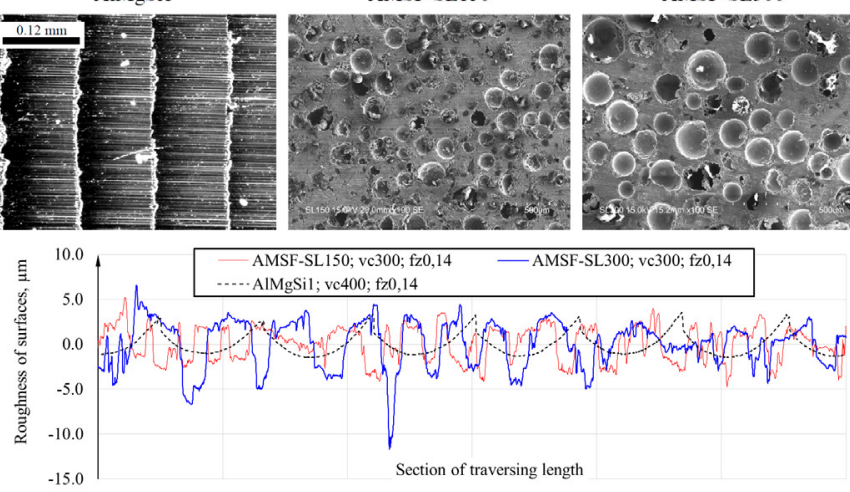

Fig. 1 Nature of the milled surfaces of AlMgSi1 aluminum alloy and AMSF (Aluminum Matrix Syntactic Foam) (Stereomicroscope: Nikon SMZ 18)
In our present article we are going to list up the common roughness parameters, widely used in the industry. Based on the data, gained from the measurements, we are going to introduce the development of certain parameters and to analyse the size of their applicability as well. We are going to refer to the arithmetical and longitudinal parameters, and the formal and hybrid features, too.

\section{The average roughness and root mean square parameters}

The average roughness ( $\mathrm{Ra})$, serving the arithmetical description of surfaces, usually characterises well the smoothness of 2D surface in case of machining conventional materials, having a homogeneous structure. The change in Ra value indicates the modification in the production process, for example, tool wear, appearance of vibrations etc. It is important to know that this parameter does not distinguish between the „valleys” and ,peaks" of the profile, and it causes a significant distortion in the surface evaluation, especially in case of materials, containing great material particles (for example, AMSF). There may be significant differences in the working behaviour of two surfaces, having the same average roughness parameters: the $\mathrm{Ra}$ value does not give any information about the longitudinal development of the profile (so-called spacing parameters) nor about the distribution around the mean line. All these details are essential in order to get to know exactly the contact, the wear and lubrication properties: from these, conclusions can be drawn, referring to the later working characteristics of the surface [14].

The substance of the root mean values $(\mathrm{Rq})$ is similar to the average roughness values, however, all arithmetical differences have to be considered in a quadratic form. As a result of it, the Rq parameter is much more sensitive to the changes on the surface (surges, indentations) and it amplifies them [14].

As it can be seen well in Fig. 2, the Ra values, measured on the milled surfaces of composite foams, are more than twice the size of the values, measured in case of machining matrix material. As regards Rq values, there may be even threefold 


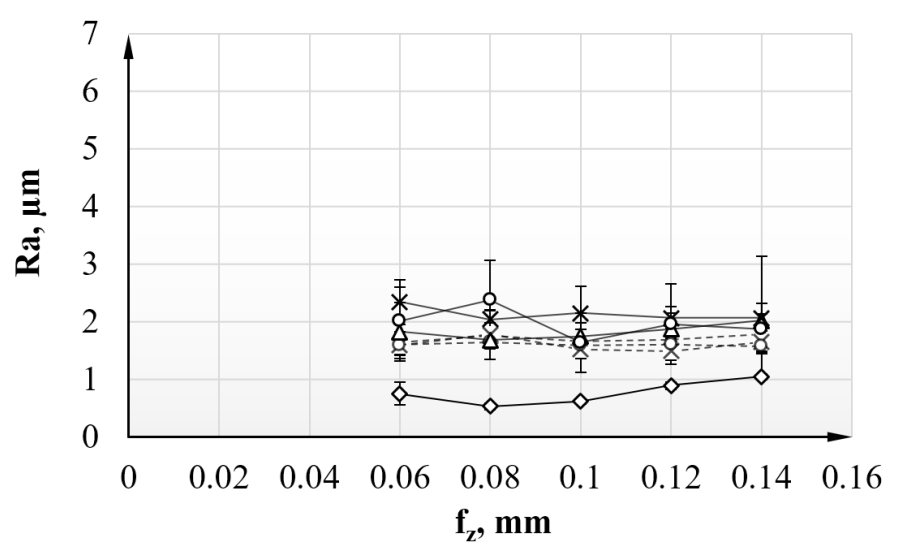

(a)

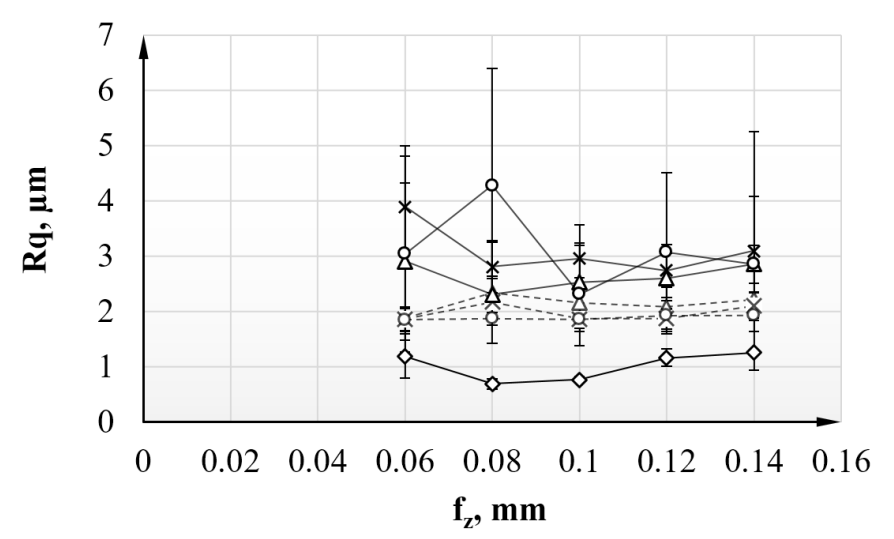

(b)

Fig. 2 Measured average roughness values (a) and root mean square values (b)

differences as the appearance of deep valleys on the profile effectively amplifies the value of the parameters.

\section{The maximum unevenness and roughness height parameters}

Although it is common in Hungary to use the average roughness (Ra) values and it may remain quasi constant on different measurement sections; at the same time, it hides the typical differences between the surface profiles. It may well happen that the Rt (maximum unevenness) and Rz (roughness height) parameters differ greatly from the average roughness values, measured on a certain surface [13]. It is increasingly true in case of machined surfaces of AMSF, divided by roughness valleys to a great extent (Fig. 3).

Compared to the average values, the Rt and Rz parameters give much more information about the surfaces, divided by significant protrusions and valleys (see in Fig. 1); evaluating them we can get much closer to the real surface structure. The Rt value means the distance between the deepest valley and the highest peak, measured on the evaluation length, it fully depends on how the grains of the matrix material and the particulates are located on the milled surface in the traction direction of the tracer. As it can be seen clearly in Fig. 3a, the Rt parameter has a quite great dispersion in values, especially in case of low values $(0.06$ and $0.08 \mathrm{~mm})$ of feed rate per tooth:

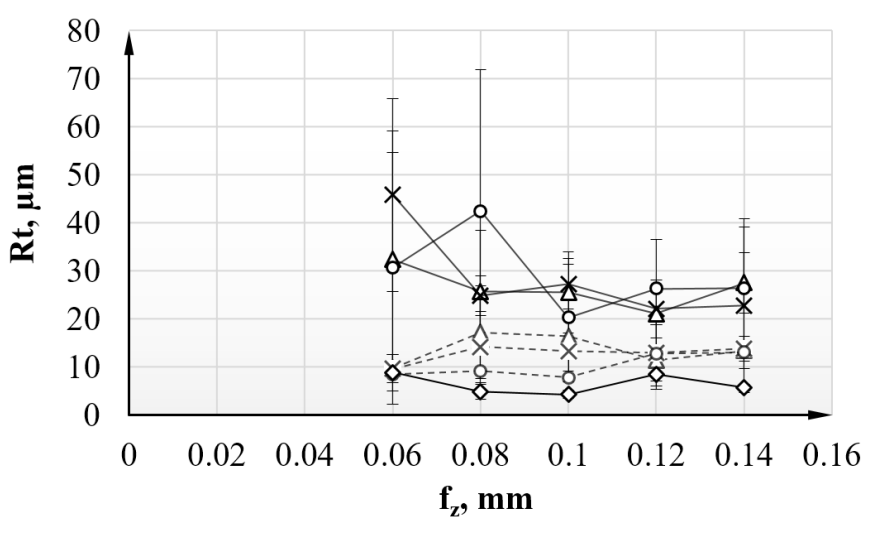

(a)

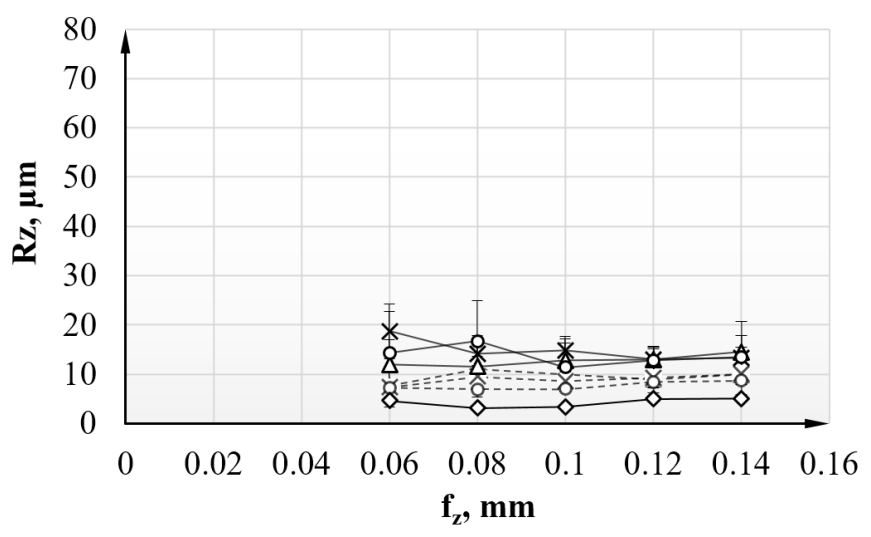

(b)

Fig. 3 Measured maximum unevenness (a) and roughness height values (b)

on one hand, it leads to the conclusion that the surface of metal foams is divided by lot of „errors” (valleys and/or missing material particulates) and has a hollow structure. On the other hand, it provides information about under what conditions the particles are cut by the tool edge, and, how the softer material granules of the matrix are spread into the valleys, developed by turning out or by cutting through the particulates. It happens absolutely in a random way, but it depens on the cutting parameters. The Rt parameter, the maximum unevenness, is used to characterise mainly components, where special „errors” (outliers), developing on the surface, have a significant importance [14]. In our case, the outliers, caused by Rt parameters, are significant mainly at low values of feed rate per tooth, therefore they provide a stable basis for the surface characterisation. As it can be seen in Fig. 3b (at the applied scale intervals) the Rz values are dwarfed by the Rt parameters. When calculating Rz values, the evaluation of roughness profile is made on 5 sampling lengths (a single sampling length is $\mathrm{L}_{\mathrm{c}}=0.8 \mathrm{~mm}$ ), after that, for each sampling length, the greatest distance between the highest peak and lowest valley (i. e. the arithmetical local extremums of the surface) will be found by the algorithm, the Rz value is given by averaging these distances. The Rz parameter provides a good information about the whole surface; furthermore, it is able to demonstrate the size differences between the reinforcements of AMSF-SL150 and AMSF-SL300 materials. 


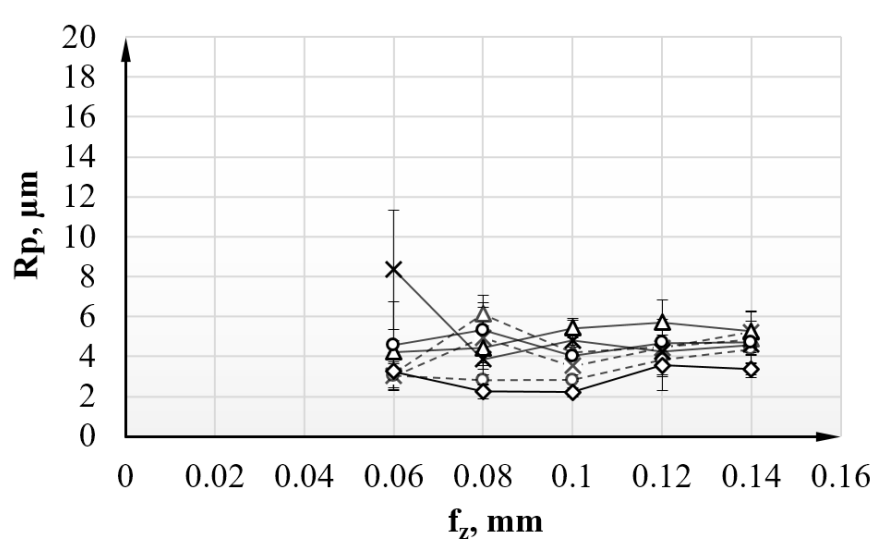

(a)

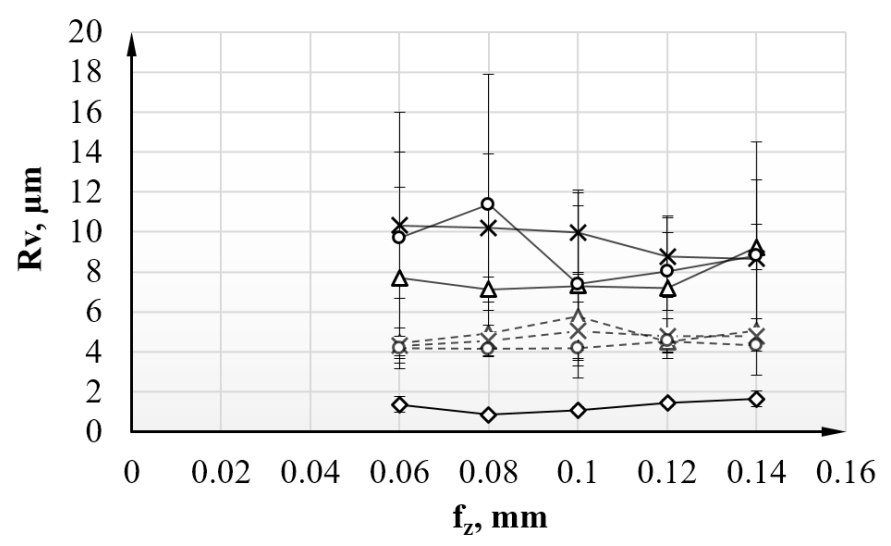

(b)

Fig. 4 The measured maximum values of peak height (a) and valley depth (b)

\section{The maximum peak height $(R p)$ and valley depth $(R v)$ of the profile}

The maximum peak height of the profile (Rp) value is calculated by averaging the coordinates of the highest peak from the mean line, defined on the basic (sampling) length. The parameter of the maximum valley depth (Rv) can be determined in a similar way [14]. In Fig. 4 the results, measured by us, are summarised.

Based on the peak height values (Rp) in Fig. $4 a$, it can be observed that in case of machining matrix aluminum this parameter has the smallest values $(2-3 \mu \mathrm{m})$ at all feed rates per tooth. In case of metal composites, the Rp values are „merged”, therefore it is not possible to make difference between the two material grades, having different particulate sizes.

The Fig. 4b demonstrates the maximum valley depths (Rv), measured in case of different settings. As it can be seen well in the figure, in case of matrix material, having a homogeneous structure, the valleys have an uniform depth, the variability of the measured data is negligibly low. The two types of metal foams can be well distinguished: in case of AMSF-SL150 metal composite, the Rv parameters are in the range of 3 and $6 \mu \mathrm{m}$ (with a really low variability), while in case of AMSF-SL300 this parameter varies in the range of 6-10 $\mu \mathrm{m}$. In case of material, having greater size of particulates, the high coefficient of variation refers to the porosity of the surface, having been machined.

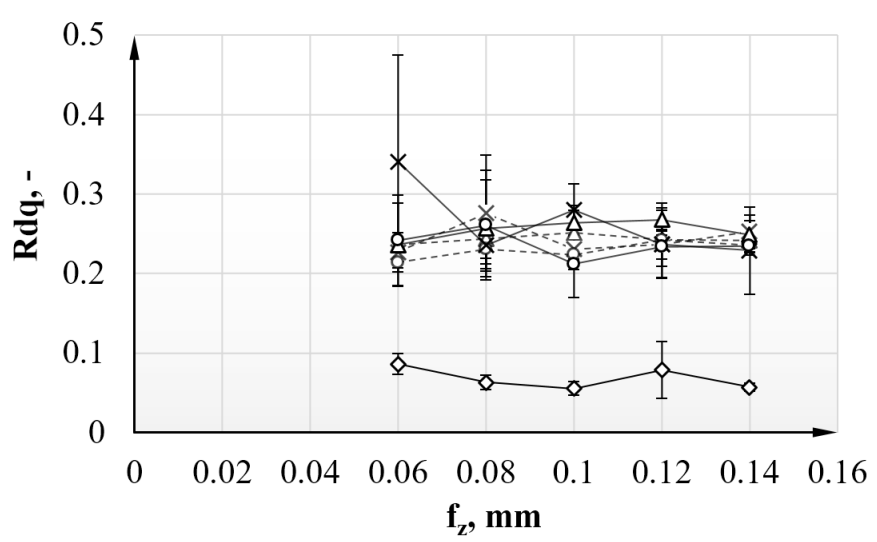

Fig. 5 The measured values of root mean square slope of the profile

In summary, it can be noticed that the parameters of the arithmetical deviations of profile, for example, the average roughness (Ra), the root mean square (Rq), the maximum unevenness (Rt), the height of roughness or height of unevenness (Rz) and the maximum profile peak height (Rp) - although they provide relevant information - cannot be considered as correct parameters in case of composite materials, having a hollow structure. From the parameters, already introduced in this chapter, the maximum valley depth (Rv) has to be highlighted: it makes possible to distinguish between the material types, but it is not possible to demonstrate clearly the effect of the cutting data based on the measured values.

\section{The root mean square slope of the profile $(R d q)$}

The Rdq value has to be classified under the hybrid parameters and gives the average slope of the peaks and valleys of the profile. It describes a geometrical feature, being able to characterise the profile amplitude independently, its value refers to the complexity of the successive profile elements.

In Fig. 5, the Rdq values are shown, measured in the case of AlMgSil aluminum matrix and two types of metal foams: they are significantly different. In the case of homogeneous aluminum matrix the value of the average slope is lower than 0.1 , while in the event of inhomogeneous metal foams this parameter has - independently from the size of particles - at least a double value. This parameter shows the significant microgeometrical difference between the profiles of the aluminum material and the metal foams, it depends on the applied feed rate per tooth only marginally.

\section{Description of the milled surface with the ratios of the parameters}

According to conversion, widespreadly used in the technical practice, the height of roughness $(\mathrm{Rz})$ is four times greater than Ra. As it is confirmed by evaluation of the measurements, carried out in the past several years, and of the experiences (mentioned by us in the published literatures [12]]), the value of the multiplication factor is not necessarily four, it deviates from four, it is usually a greater number. In the case of metal 


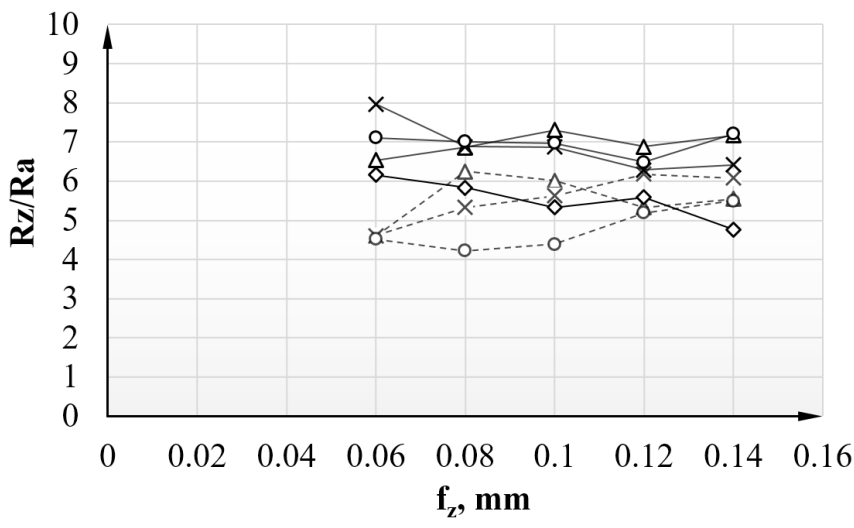

(a)

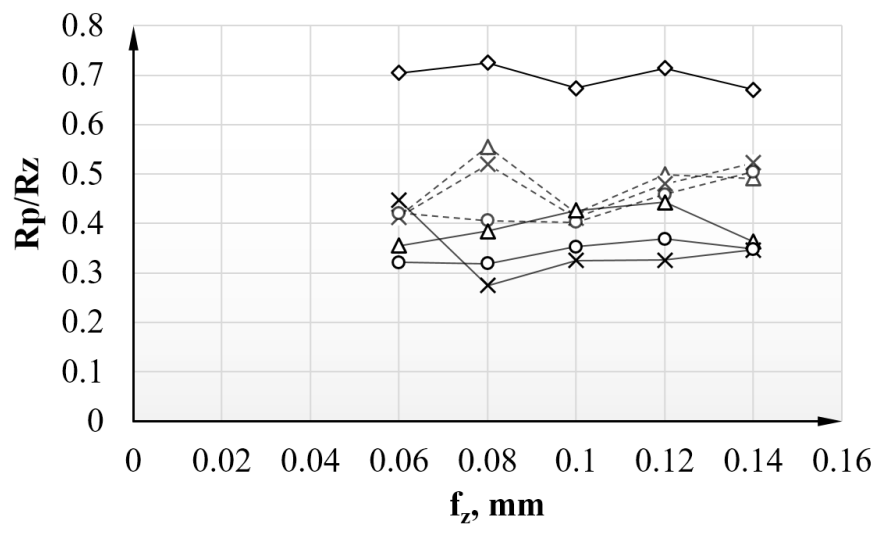

(b)

Fig. 6 The ratio of unevenness height and average roughness (a) and the ratio of maximum peak height and unevenness height of profile (b)

foams, the ratio of $\mathrm{Rz} / \mathrm{Ra}$ parameters is between four and eight (Fig. 6a). As it has already been mentioned in the present article, the measured Rt parameters are approx. two times greater than the Rz values in case of hollow surface structure of metal foams. At the same time, it means that the arithmetical distances between the peak heights and valley depths, i. e. the real differences in the arithmetical profile heights $(\mathrm{Rt} / \mathrm{Ra})$ are 8-16 times greater, than the values, given by the average roughness.

Another ratio, used in the literature and studied by us, is the proportion of $\mathrm{Rp} / \mathrm{Rz}$. If the ratio of $(\mathrm{Rp} / \mathrm{Rz})$ peak height and unevenness height is greater than 0.5 , then the peak zone is „needle-like", if it is less than 0.5 , then the machined surface is much more favourable: the material has a rounded, ,saturated" profile [14]. In Fig. 6b, the measured ratios of $\mathrm{Rp} / \mathrm{Rz}$ are shown in case of all the three examined materials. After machining matrix material, the ratio of the measured $\mathrm{Rp} / \mathrm{Rz}$ is nearly 0.7 in case of every value of feed rate per tooth, applied during the tests, and it clearly refers to the sharp peak zone. In case of metal composites, the ratio of $\mathrm{Rp} / \mathrm{Rz}$ is - in most cases - lower than 0.5 , according to the literature [14] it is typical for the robust, rounded material profiles. It means that the surface structure of the milled metal foams looks like so that the cavities, left behind by the cutting edge when turning out / crushing / cutting through the microballoons, are filled in by the matrix material relatively evenly. The greater the size of the reinforcing particles (e.g. SL300) is, the greater place is available for the matrix material, having a low strength, to be pressed in (,smeared into the holes/cavities”).

It can be concluded that the machined surface of AMSF materials, having inhomogeneous structure, may not be described by the chosen hybrid parameters nor by the ratio of $\mathrm{Rz} / \mathrm{Ra}$ parameters in an adequate way. The ratio of $\mathrm{Rp} / \mathrm{Rz}$ parameters is a very important feature in the tribology: based on it, it can be clearly demonstrated that in case of milling, the ,peaked" profile structure of the matrix material significantly differs from the rounded surface structures of metal foam materials.

\section{Conclusions}

In our article the differences of the milled surface structures of two metal foam types and aluminum alloy, serving as matrix material of the metal foams, have been analysed in details. It has been noted that the parameters of arithmetical unevennesses of profile (such as the average roughness ( $\mathrm{Ra}$ ), the root mean square (Rq), the maximum unevenness (Rt), the height of roughness or unevenness $(\mathrm{Rz})$, the maximum peak height (Rp) and the maximum valley depth (Rv)) can be applied in themselves hardly or with some consideration in order to describe the machined surfaces of composite materials, tested by us.

It has been also presented in our study that the machined surfaces of materials, having inhomogeneous structure, can be characterised with the ratio of parameters $(\mathrm{Rz} / \mathrm{Ra})$ only to a very limited extent. With the selected hybrid parameter (Rdq) and the ratio of $\mathrm{Rp} / \mathrm{Rz}$ can we identify a significant difference between the homogeneous aluminum alloy and the metal foams.

\section{Acknowledgement}

Our article has been prepared with the support of Dr. habil. Imre Orbulov and Dr. Kornél Májlinger (providing the tested materials), Dr. Sándor Sipos and Dr. Béla Palásti Kovács (professional consultation), as well as Attila Bohner (providing the milling tools).

\section{References}

[1] Davim, J. P. "Machining of Metal Matrix Composites." Springer, London, 2012. https://doi.org/10.1007/978-0-85729-938-3

[2] Taha, M. A., El-Sabbagh, A. M., Taha, I. M. "Trends in Composite Materials and their Design." Key Engineering Materials. 425, 2010.

[3] Saxena, M., Pappu, A., Sharma, A., Haque, R., Wankhede, S. "Composite Materials from Natural Resources: Recent Trends and Future Potentials." In: Advances in Composite Materials - Analysis of Natural and Man-Made Materials. INTECH, 2011.

https://doi.org/10.5772/18264

[4] HOFFMANN GROUP(THE QUALITY COMPANY) "Die Zukunft heißt Leichtbau." (The future is lightweight.), Garant Zerspanungswerkzeuge für Alu, Polymere, ADI, Composites und Superlegierungen. Hoffmann Hungary Quality Tools Kft., München, KW1326 DE, 2013. (in German) 
[5] Gácsi, Z., Simon, A., Pázmán, J. "Fémkompozitok." (Metal Matrix Composites.) Miskolci Egyetemi Kiadó, 2011. (in Hungarian).

[6] Islam, M. M., Kim, H. S. "Novel syntactic foams made of ceramic hollow microspheres and starch: theory, structure and properties." Journal of Materials Science. 42(15), pp. 6123-6132. 2007.

https://doi.org/10.1007/s10853-006-1091-7

[7] Orbulov, I. N., Dobranszky, J., Nemeth, A. "Microstructural characterisation of syntactic foams." Journal of Materials Science. 44(15), pp. 4013-4019. 2009.

https://doi.org/10.1007/s10853-009-3552-2

[8] Orbulov, I. N., Ginsztler, J. "Compressive characteristics of metal matrix syntactic foams." Composites Part A: Applied Science and Manufacturing. 43(4), pp. 553-561. 2012.

https://doi.org/10.1016/j.compositesa.2012.01.008

[9] Szalóki, I., Viharos, Zs. J. "Keményfém és gyémánt élanyagok teljesítőképességének elemzése alumínium mátrixú kompozit síkmarásakor." (Performance analyzis on hard metal and diamond cutting tool materials for plate drilling of aluminium based matrix composites.). Gépgyártás. 55, pp. 87-92. 2016. (in Hungarian)

[10] Szalóki, I., Sipos, S., Viharos, J. "Aluminum-Based MMC Machining with Carbide Cutting Tool." Key Engineering Materials. 686, pp. 149154. 2016.

https://doi.org/10.4028/www.scientific.net/KEM.686.149
[11] Palásti-Kovács, B., Sipos, S., Biró, Sz. "The Mysteries of the Surface First Part: The Characteristic Features of the Microgeometry of the Machined Surface." Acta Polytechnica Hungarica. 11(5), pp. 5-24. 2014. https://doi.org/10.127000/APH11.05.2014.05.1

[12] Szalóki, I. "Analysis of drilling surface microgeometry." In: 2nd Regional Conference - Mechatronics in Practice and Education, Subotica, Serbia, Dec. 5-6, 2013, pp. 111-114.

[13] Palásti-Kovács, B., Sipos, S., Szalóki, I. "Experimental research of cutting performance and quality abilities of modern drilling tools." Key Engineering Materials. 581, pp. 32-37. 2014.

http://www.scientific.net/KEM.581.32

[14] Czifra, A. "Útmutató a mikrotopográfiai vizsgálatok laborgyakorlatához." (A guide to microtopographic laboratory practice.), Obuda University, Budapest, 2011. (in Hungarian)

[15] Palasti-Kovacs, B., Sipos, S., Czifra, A. "“Rz = 4*Ra” és egyéb érdességi értelmezések a forgácsolt felületek értékelésében." (Interpretation of "Rz $=4 \times \mathrm{Ra} "$ and other roughness parameters in the evaluation of machined surfaces.) Devices, Tools and Machines. pp. 20-24. 2012. (in Hungarian) 